\title{
Normative Orbital Measurement Based on Computed Tomography Imaging in Tertiary Care Hospital, Bangalore, Karnataka
}

\section{ABSTRACT}

Introduction: The orbit is an anatomically complex region. Clear idea of the normal orbital measurements is needed for the diagnosis and management of the various diseases that may affect the orbit like optic neuritis, optic nerve glioma, meningioma, proptosis and exophthalmos.

Aim: To evaluate normative orbital measurement at tertiary care hospital in Bangalore, Karnataka in Indian population based on Non Enhanced Computed Tomography (NECT) imaging.

Materials and Methods: A cross-sectional observational study of 100 patients referred to a tertiary care centre for NECT of the brain for diseases other than those of the orbits was conducted. Patients having any orbital disorder, surgery or trauma and having metallic implants were excluded from the study. The patients of all age groups and either sex were included. The horizontal orbital diameter, vertical orbital diameter, orbital index, optic nerve complex, globe position, interorbital diameter and interzygomatic line measurements were calculated for 100 patients, i.e., total of 200 orbits using both axial and direct coronal CT images. Mean measurements of these parameters were calculated. Scans were performed on Siemens Somatom Perspective 128 slice multidetector CT scanner. All statistical analysis was performed using Statistical Package for The Social Sciences (SPSS) for windows software (SPSS Inc. Illinois, Chicago, USA).

Results: The mean orbital index was 118.6 and 118.3 for right and left orbit, respectively. It was derived from mean horizontal orbital diameter of $32.5 \mathrm{~mm}$ and $31.7 \mathrm{~mm}$ of right and left orbit, respectively and mean vertical orbital diameter of $38.4 \mathrm{~mm}$ and $37.4 \mathrm{~mm}$ of right and left orbit, respectively. Mean optic nerve sheath complex diameter was $5.2 \mathrm{~mm}$ and $5.4 \mathrm{~mm}$ for right and left orbit, respectively, while mean globe position measurements $6.7 \mathrm{~mm}$ and $6.8 \mathrm{~mm}$ of right and left orbit, respectively. Average interorbital distance was $22.9 \mathrm{~mm}$ and average interzygomatic distance $97.1 \mathrm{~mm}$.

Conclusion: The present study has given normative mean measurements for various orbital structures that are essential to ophthalmologists and radiologists to differentiate normal from abnormal dimensions which is likely to be helpful in accurate assessment of various orbital pathologies.

\section{INTRODUCTION}

The orbit is a structurally complex area. A better idea of the normal dimension of orbit plays key role in the diagnosis and management of the various orbital disease and pathology like optic neuritis, optic nerve glioma, meningioma, proptosis and exophthalmos. The present available data of normal orbital measurement are mainly from western countries [1]. Sheikh $M$ et al., demonstrated normal orbital values in Middle Eastern population which was used in assessment of thyroid opthalmopathy [2]. Chatdokmaiprai $\mathrm{C}$ et al., demonstrated normal interorbital distance in Thai population [3]. Availability of such kind of data is lacking from Indian subcontinent. The purpose of this study was to evaluate normative orbital measurement at tertiary care hospital in Indian population based on NECT imaging. Orbital radiograph, ultrasound and MRI orbit also can be used for radiological assessment of normal orbital measurements.

\section{MATERIALS AND METHODS}

A cross-sectional observational study was done from October 2019 to March 2020 at teritary care center, Bangalore, Karnataka, India. A total of 100 patients came for NECT brain for diagnosis of disease except orbital pathology. Ethical committee approval was taken for conducting the study, and its number is RRMCHIEC/57/2019-2020.

According to Yamane formula, sample size was calucutated that is: $\mathrm{n}=\mathrm{N} /\left(1+\mathrm{Ne}^{\star} 2\right)$

Where,
$\mathrm{N}=$ known population size, which here is average number of patients visiting our Radiology Department for CT Brain (except trauma; orbital pathologies cases), which were 22 per month. Average was calculated by referring data of number of patients who visited in past one year (2019 to 2020) for CT Brain excluding trauma and orbital pathologies cases. And the study period was of 6 months, so $\mathrm{N}=22 \times 6=132$.

$\mathrm{e}=$ margin of error (for 95\% confidence level, margin of error $=0.05$ ) $\mathrm{n}=132 / 1+132 \times(0.05)^{2}$

$n=132 / 1.33=99.248 \approx 100$.

Inclusion and Exclusion criteria: Patients with history of any orbital disorder, surgery or trauma and having metallic implants were excluded. Age group between 5 to 85 years and either sex subjects were included in this study.

\section{Procedure}

Scans were performed on Siemens Somatom Perspective 128 slice multi-detector CT scanner. Bone and soft tissue windows were used according to the contemporary protocols [1]. Right and left orbital measurements were calculated differently. The horizontal and vertical diameters of the orbit were estimated by measuring widest distance between medial lateral and superior inferior orbital walls, respectively [Table/Fig-1a].

Orbital Index (OI) was calculated using the following formula:

$\mathrm{Ol}=\frac{\text { Maximum vertical distance of the orbital cavity }}{\text { Maximum horizontal distance }} \times 100$ 
Interorbital distance was measured on axial scan by estimating the minimum distance between medial orbital walls [Table/Fig-1b]. Interzygomatic distance estimated by measuring the maximum distance in-between the points on zygomatic arch's anterior part [Table/Fig-1b]. The optic nerve diameter (maximum) was measured with its sheath on coronal scans. (Optic nerve sheath complex diameter) [Table/Fig-2]. On axial scan in the mid globe, on slicing the distance between the posterior ocular surface and the interzygomatic line was used for estimating globe position [1].
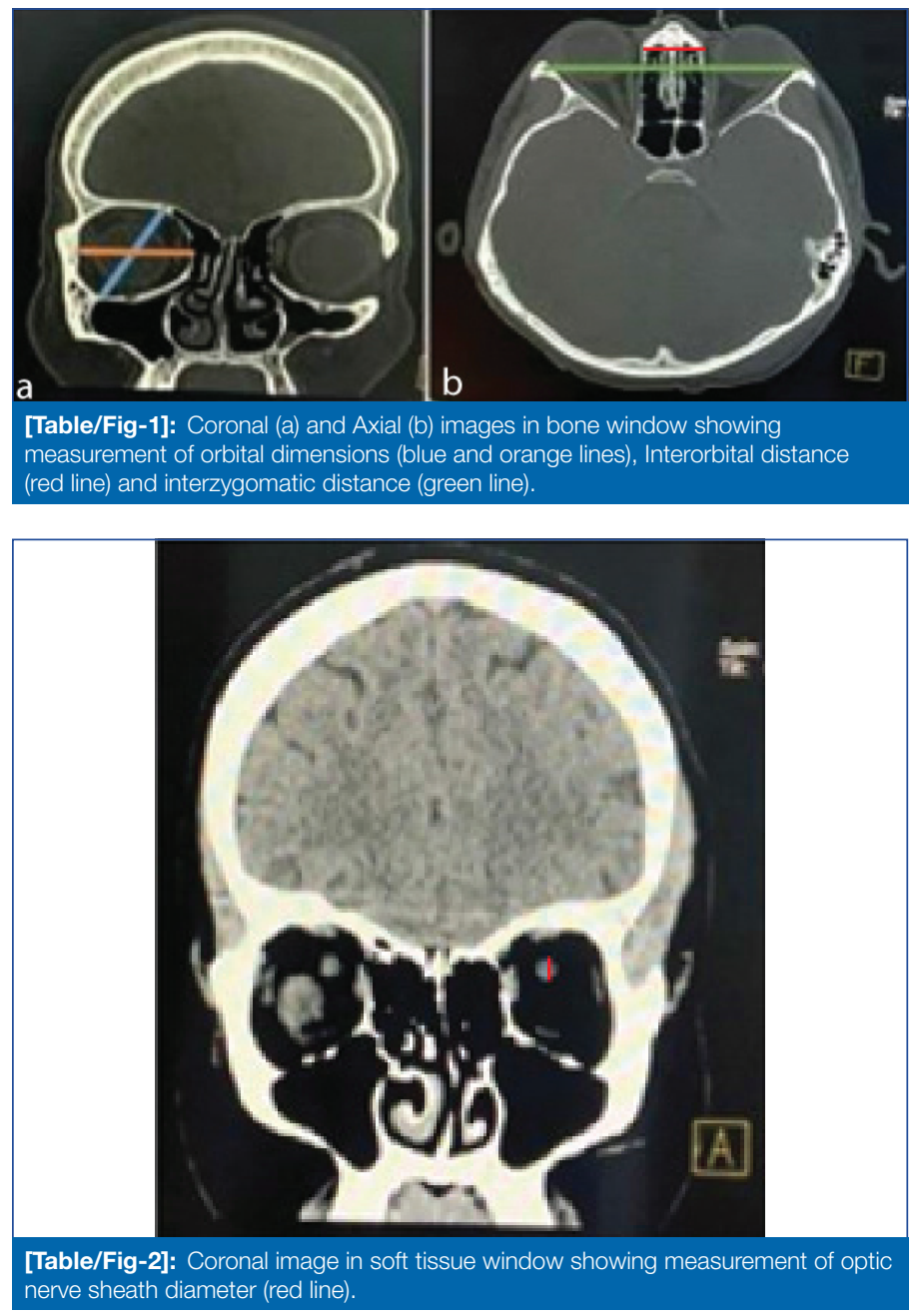

\section{STATISTICAL ANALYSIS}

Statistical analysis performed using Statistical Package for The Social Sciences (SPSS) Version V27 for windows software (SPSS Inc. Illinois, Chicago, USA). The means of right and left sides and between the male and female samples were compared for significance using the student unpaired t-test. Confidence interval of 95\% was assumed, and the differences were considered significant at $<0.05$.

\section{RESULTS}

Out of these 100 patients, majority were males (67\%). The age ranged between 5 and 85 years with mean age in years $42 \pm 5$ years. According to age wise distribution, 16-25 years and 26-35 years groups had maximum number of patients which was 19 in number, while 36-45 years and 46-55 years of groups had 17 patients each [Table/Fig-3].

In the overall population, mean orbital index was 118.6 and 118.3 for right and left orbit, respectively. It was derived from mean horizontal orbital diameter of $32.5 \mathrm{~mm}$ and $31.7 \mathrm{~mm}$ of right and left orbit respectively and mean vertical orbital diameter of $38.4 \mathrm{~mm}$ and $37.4 \mathrm{~mm}$ of right and left orbit, respectively [Table/Fig-4].

In females, optic nerve sheath complex diameter for right and left eye was $5.1 \mathrm{~mm}$ and $5.3 \mathrm{~mm}$, respectively while in males, it was $5.2 \mathrm{~mm}$ and $5.4 \mathrm{~mm}$, respectively [Table/Fig-5,6].

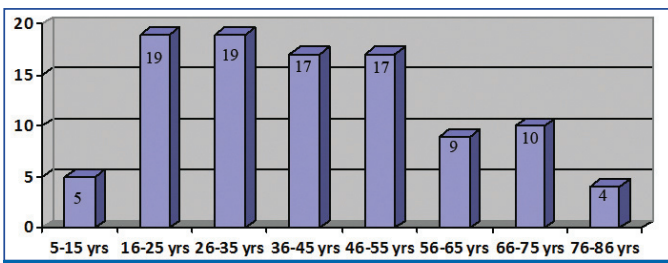

$\square$ Number of patient

5-15 yrs $16-25$ yrs $26-35$ yrs $36-45$ yrs $46-55$ yrs $56-65$ yrs $66-75$ yrs $76-86$ yrs

[Table/Fig-3]: Chart demonstrates number of patients according to the age.

\begin{tabular}{|c|c|c|c|c|}
\hline Overall parameter & & Right orbit & Left orbit & $\mathrm{p}$-value \\
\hline \multirow{4}{*}{$\begin{array}{l}\text { Horizontal orbital } \\
\text { diameter }\end{array}$} & Mean (mm) & 32.5 & 31.7 & \multirow{4}{*}{0.0278} \\
\hline & Minimum (mm) & 24.8 & 23.5 & \\
\hline & Maximum (mm) & 38.3 & 39.8 & \\
\hline & SD & 2.24 & 2.83 & \\
\hline \multirow{4}{*}{$\begin{array}{l}\text { Vertical orbital } \\
\text { diameter }\end{array}$} & Mean (mm) & 38.4 & 37.4 & \multirow{4}{*}{0.0091} \\
\hline & Minimum (mm) & 32.6 & 22.9 & \\
\hline & Maximum (mm) & 45.6 & 43.4 & \\
\hline & SD & 2.38 & 2.96 & \\
\hline \multirow{4}{*}{ Orbital index } & Mean (mm) & 118.6 & 118.3 & \multirow{4}{*}{0.8282} \\
\hline & Minimum (mm) & 100.8 & 88.4 & \\
\hline & Maximum (mm) & 160 & 159.5 & \\
\hline & SD & 8.96 & 10.5 & \\
\hline \multirow{4}{*}{$\begin{array}{l}\text { Optic nerve } \\
\text { complex }\end{array}$} & Mean (mm) & 5.2 & 5.4 & \multirow{4}{*}{0.1589} \\
\hline & Minimum (mm) & 2.9 & 3.1 & \\
\hline & Maximum (mm) & 8.2 & 8.1 & \\
\hline & $\mathrm{SD}$ & 1.0 & 1.0 & \\
\hline \multirow{4}{*}{ Globe position } & Mean (mm) & 6.9 & 7.1 & \multirow{4}{*}{0.5762} \\
\hline & Minimum (mm) & 0.5 & 0.7 & \\
\hline & Maximum (mm) & 12.8 & 13.7 & \\
\hline & SD & 2.45 & 2.60 & \\
\hline
\end{tabular}

[Table/Fig-4]: Shows mean ( $\mathrm{mm})$, minimum $(\mathrm{mm})$ and maximum $(\mathrm{mm})$ values of horizontal and vertical orbital diameter, orbital index, optic nerve complex and globe position in the overall population.

Student unpaired t-test was used; SD: Standard deviation; $(<0.05$, Statistically significant $)$

\begin{tabular}{|c|c|c|c|c|}
\hline Parameter in female & & Right orbit & Left orbit & $p$-value \\
\hline \multirow{4}{*}{$\begin{array}{l}\text { Horizontal orbital } \\
\text { diameter }\end{array}$} & Mean (mm) & 37.4 & 36.3 & \multirow{4}{*}{0.6814} \\
\hline & Minimum (mm) & 24.8 & 23.5 & \\
\hline & Maximum (mm) & 34.3 & 36 & \\
\hline & SD & 2.37 & 3.23 & \\
\hline \multirow{4}{*}{ Vertical orbital diameter } & Mean $(\mathrm{mm})$ & 39.9 & 36.3 & \multirow{4}{*}{$<0.0001$} \\
\hline & Minimum (mm) & 31.9 & 22.9 & \\
\hline & Maximum (mm) & 41.2 & 41 & \\
\hline & SD & 2.05 & 3.48 & \\
\hline \multirow{4}{*}{ Orbital index } & Mean (mm) & 120.2 & 119 & \multirow{4}{*}{0.6814} \\
\hline & Minimum (mm) & 106.7 & 101.1 & \\
\hline & Maximum (mm) & 160 & 159.5 & \\
\hline & SD & 10.28 & 13.18 & \\
\hline \multirow{4}{*}{ Optic nerve complex } & Mean $(\mathrm{mm})$ & 5.1 & 5.3 & \multirow{4}{*}{0.3958} \\
\hline & Minimum (mm) & 3.4 & 3.1 & \\
\hline & Maximum (mm) & 7.1 & 7.2 & \\
\hline & SD & 0.93 & 0.97 & \\
\hline \multirow{4}{*}{ Globe position } & Mean (mm) & 7.3 & 7.7 & \multirow{4}{*}{0.5074} \\
\hline & Minimum (mm) & 0.5 & 2.7 & \\
\hline & Maximum (mm) & 12.8 & 11.4 & \\
\hline & SD & 2.54 & 2.33 & \\
\hline
\end{tabular}

[Table/Fig-5]: Shows mean ( $\mathrm{mm})$, Minimum ( $\mathrm{mm}$ ) and Maximum $(\mathrm{mm})$ values of horizontal and vertical orbital diameter, orbital index, optic nerve complex and globe position in females.

Student unpaired t-test was used; SD: Standard deviation; $(<0.05$, Statistically significant $)$

In males, horizontal orbital diameter and vertical orbital diameter showed statistical significance for right and left eyes measurements. 


\begin{tabular}{|c|c|c|c|c|}
\hline $\begin{array}{l}\text { Parameters in } \\
\text { males }\end{array}$ & & Right orbit & Left orbit & $\mathrm{p}$-value \\
\hline \multirow{4}{*}{$\begin{array}{l}\text { Horizontal } \\
\text { orbital diameter }\end{array}$} & Mean (mm) & 33.1 & 32.3 & \multirow{4}{*}{0.0353} \\
\hline & Minimum (mm) & 27.8 & 25.9 & \\
\hline & Maximum (mm) & 38.3 & 39.8 & \\
\hline & SD & 1.89 & 2.43 & \\
\hline \multirow{4}{*}{$\begin{array}{l}\text { Vertical orbital } \\
\text { diameter }\end{array}$} & Mean (mm) & 39 & 38 & \multirow{4}{*}{0.0192} \\
\hline & Minimum (mm) & 37.6 & 31.8 & \\
\hline & Maximum (mm) & 45.6 & 43.4 & \\
\hline & SD & 2.36 & 2.52 & \\
\hline \multirow{4}{*}{ Orbital index } & Mean (mm) & 117.8 & 117.9 & \multirow{4}{*}{0.9464} \\
\hline & Minimum (mm) & 100.8 & 95.7 & \\
\hline & Maximum (mm) & 140.7 & 143.9 & \\
\hline & SD & 8.21 & 8.97 & \\
\hline \multirow{4}{*}{$\begin{array}{l}\text { Optic nerve } \\
\text { complex }\end{array}$} & Mean (mm) & 5.2 & 5.4 & \multirow{4}{*}{0.2700} \\
\hline & Minimum (mm) & 2.9 & 3.2 & \\
\hline & Maximum (mm) & 8.2 & 8.1 & \\
\hline & SD & 1.04 & 1.05 & \\
\hline \multirow{4}{*}{ Globe position } & Mean (mm) & 6.7 & 6.8 & \multirow{4}{*}{0.8204} \\
\hline & Minimum (mm) & 2 & 0.7 & \\
\hline & Maximum (mm) & 12.3 & 13.7 & \\
\hline & SD & 2.39 & 2.69 & \\
\hline
\end{tabular}

[Table/Fig-6]: Shows mean ( $\mathrm{mm})$, Minimum $(\mathrm{mm})$ and Maximum $(\mathrm{mm})$ values of horizontal and vertical orbital diameter, orbital index, optic nerve complex and globe position in males.

Student unpaired $t$-test was used; SD: Standard deviation; $(<0.05$, Statistically significant $)$

The p-value was 0.0353 and 0.0192 of horizontal orbital diameter and vertical orbital diameter for right and left eye measurements in males respectively [Table/Fig-6]. The mean interorbital distance was $25.4 \mathrm{~mm}$ in females and $23.1 \mathrm{~mm}$ in males. The mean interzygomatic distance was $97.2 \mathrm{~mm}$ in females and $97.9 \mathrm{~mm}$ in males [Tables/Fig-7]. Horizontal orbital diameter of right and left eye of male and female shows the statistical significance ( $p$-value <0.0001) [Table/Fig-8].

\begin{tabular}{|c|c|c|c|}
\hline Parameters & & $\begin{array}{l}\text { Distance } \\
\text { (in } \mathrm{mm} \text { ) }\end{array}$ & $\mathrm{p}$-value \\
\hline \multirow{3}{*}{$\begin{array}{l}\text { Average interorbital } \\
\text { distance }\end{array}$} & Overall (SD) & $22.9(2.78)$ & \multirow{3}{*}{0.0001} \\
\hline & Males (SD) & $23.1(2.76)$ & \\
\hline & Females (SD) & $25.4(2.67)$ & \\
\hline \multirow{3}{*}{$\begin{array}{l}\text { Average interzygomatic } \\
\text { distance }\end{array}$} & Overall SD & $97.1(4.69)$ & \multirow{3}{*}{0.4498} \\
\hline & Males (SD) & $97.9(4.22)$ & \\
\hline & Females (SD) & $97.2(4.57)$ & \\
\hline
\end{tabular}

[Table/Fig-7]: Shows average interorbital distance and average interzygomatic distance in overall population, males and females.

Student unpaired t-test was used: $(<0.05$, Statistically significant $)$

\begin{tabular}{|l|c|c|c|c|c|}
\hline \multirow{2}{*}{ Parameters } & \multicolumn{2}{|c|}{ Male } & \multicolumn{2}{c|}{ Female } & \multirow{2}{*}{ p-value } \\
\cline { 2 - 5 } & Mean & SD & Mean & SD & - \\
\hline Right horizontal orbtal diameter & 33.1 & 1.89 & 37.4 & 2.37 & $<0.0001$ \\
\hline Left horizontal orbital diameter & 32.3 & 2.43 & 36.3 & 3.23 & $<0.0001$ \\
\hline Right vertical orbital diameter & 39 & 2.36 & 39.9 & 2.05 & 0.0645 \\
\hline Left vertical orbital diameter & 38 & 2.52 & 36.3 & 3.48 & 0.0064 \\
\hline Right orbital index & 117.8 & 8.21 & 120.2 & 10.28 & 0.2098 \\
\hline Left orbital index & 117.9 & 8.97 & 119 & 13.18 & 0.6244 \\
\hline Right optic nerve complex & 5.2 & 1.04 & 5.1 & 0.93 & 0.3519 \\
\hline Left optic nerve complex & 5.4 & 1.05 & 5.3 & 0.97 & 0.6473 \\
\hline Right globe postion & 6.7 & 2.39 & 7.3 & 2.54 & 0.2504 \\
\hline Left globe postion & 6.8 & 2.69 & 7.7 & 2.33 & 0.1039 \\
\hline
\end{tabular}

[Table/Fig-8]: Shows mean ( $\mathrm{mm}$ ) and Standard Deviation (SD) values of horizontal and vertical orbital diameter, orbital index, optic nerve complex and globe position in males and females.

Student unpaired t-test was used

\section{DISCUSSION}

Normative measurements act as a standard for evaluation of orbital disease. Based on race, ethnicity and religion, various previous study reports of normative measurements show slight variation and normative data based on imaging doesn't exist in our knowledge. Therefore, this study will be useful in providing such normative data in Indian population. Orbital dimensions are important in the preoperative planning for post-trauma reconstructive surgery [1].

Gupta $\vee$ et al., study based on CT measurements had calculated the mean horizontal diameter $37.1 \mathrm{~mm}$ and $36.69 \mathrm{~mm}$ for right and left orbits, respectively. The vertical orbital diameter was $37.9 \mathrm{~mm}$ and $37.6 \mathrm{~mm}$ for right and left orbits, respectively. Orbital index of right and left orbit was 97 and 103, respectively [1].

Mekala D et al., had done study on south Indian dry skulls, in which they have found mean horizontal diameter of $41.7 \mathrm{~mm}$ for the right orbit and $41.8 \mathrm{~mm}$ for the left orbit. The vertical orbital diameter was $35.5 \mathrm{~mm}$ and $35.3 \mathrm{~mm}$ for right and left orbits, respectively. Orbital index of right and left orbit was 85.2 and 84.8, respectively [4].

Dhanwate $A D$ and Gaikwad MD, from Aurangabad had done study on the dry skull in Indian population. They found that in the male, mean horizontal diameter was $37.52 \mathrm{~mm}$ for the right orbit and $37.08 \mathrm{~mm}$ for the left orbit. The vertical orbital diameter was $32.64 \mathrm{~mm}$ and $32.39 \mathrm{~mm}$ for right and left orbits, respectively. Orbital index of right and left orbit was 87.28 and 87.66 , respectively. In females, the mean vertical orbital diameter for right and left orbits were 32.55 and $32.31 \mathrm{~mm}$, respectively. Mean horizontal diameter was 37.25 and $36.67 \mathrm{~mm}$ of right and left orbits respectively. Orbital index was 87.52 and 88.24 of right and left orbits, respectively [5].

As NECT for measurement of these orbital dimensions were used, therefore values in the present study are higher. It may be because of variation in genetics, race and methodologies. In Khademi $Z$ and Bayat $P$, study based on Iranian population showed average vertical diameter was lesser and horizontal orbital diameter was higher in comparison with our study [6].

If optic nerve complex diameter is increased, it is an indirect indicator of elevated intracranial pressure. This measurement is useful in diagnosing glaucoma, Graves's orbitopathy, patency of ventriculoperitoneal shunt, traumatic brain injury or other causes of raised intracranial pressure. Average optic nerve diameter was $5.3 \mathrm{~mm}$ in this study which is comparatively higher than the Nugent RA et al., which showed $4.2 \mathrm{~mm}$ [7]. Lee JS et al., study showed $3.4 \mathrm{~mm}$ and Dubost $\mathrm{C}$ et al., study showed range between 4.3 and $4.8 \mathrm{~mm}[8,9]$.

The average interzygomatic distance was measured 97.9 and $97.2 \mathrm{~mm}$ in the males and females, respectively. It ranged from $81.2 \mathrm{~mm}$ to $107.5 \mathrm{~mm}$ in this study. While in Lee JS et al., study, the average interzygomatic distance was measured $103.8 \mathrm{~mm}$ and $101.5 \mathrm{~mm}$ in males and females respectively which was comparatively litter higher than our study [8].

Sound knowledge of normal interorbital distance is very much important. Increased interorbital distance signifies orbital hypertelorism which is a manifestation of craniofacial dysplasia. It is associated with craniosynostosis and holoprosencephaly. In this study, interorbital diameter was found to be $23.1 \mathrm{~mm}$ and $25.4 \mathrm{~mm}$ in the male and female, respectively and was higher in the female as compare to the male. It is statistically significant ( $p$-value $=0.0001$ ).

In contrast to this study, Mafee MF et al., study on 400 patients based on NCCT shows mean interorbital diameter of $26.7 \mathrm{~mm}$ in the male and $25.6 \mathrm{~mm}$ in the female [10]. In an anthropometric analysis, among ethnic south Indian adults, the mean intercanthal distance was found to be $34.27 \pm 3.57 \mathrm{~mm}$ and $33.41 \pm 3.09 \mathrm{~mm}$ in the male and female, respectively [11]. We have also measured globe position in our study which is helpful to diagnose the exophthalmos. Globe position, in the female was $7.3 \mathrm{~mm}$ and $7.7 \mathrm{~mm}$ in the right 
and left orbit respectively, while in the male it was $6.7 \mathrm{~mm}$ and 6.8 $\mathrm{mm}$, respectively. Lee JS et al., study shows mean value of globe position $11.7 \mathrm{~mm}$ which is quite higher than our study [8]. It may be due to difference in ethnicity and genetics.

Orbital index for right and left eyes is 118.6 and 118.3 in present CT based study while it is comparatively less in the study of Kumar A and Nagar $M$, which is based on dry skull measurements and shows orbital index measurement 80.49 for the left eye and 79.65 for the right eye. They have classified the orbital index into the three categories. Orbital index if 89 or above megaseme, between 89 to 83 mesoseme and 83 or less microsome. According to this classification our study comes under the megaseme [12]

Another study based on the orbital dimension using dry skulls by Kaur $\mathrm{J}$ et al., shows mean right vertical diameter $31.9 \mathrm{~mm}$ and mean left vertical diameter $32.2 \mathrm{~mm}$, which is lower than our study while, it shows mean right horizontal diameter $39.7 \mathrm{~mm}$ and mean left horizontal diameter $38.8 \mathrm{~mm}$, which is higher than our study [13].

Jullabussapa $\mathrm{N}$ et al., study based on CT measurements of facial parameters shows mean interzygomatic distance of $99 \mathrm{~mm}$ in above 18 to 19 years age group which is almost equal to our study which is $97.1 \mathrm{~mm}$. In our study, mean diameter of interzygomatic distance in the male and female is 97.9 and 97.2 , respectively while it is 100.8 and 96.0 in the Jullabussapa $\mathrm{N}$ et al., study in above 18 to 19 years age group [14].

\section{Limitation(s)}

Small sample size and calculating orbital dimension on crosssectional imaging, while it should be ideally calculated on dry skull bone specimens.

\section{CONCLUSION(S)}

NECT is a simple and effective way to measure the orbital measurements. In conclusion, we like to say that this study gives various normative orbital dimensions which are useful in diagnosis of various orbital diseases, in Indian population, by ophthalmologists, radiologists and neurosurgeons.

\section{REFERENCES}

[1] Gupta V, Prabhakar A, Yadav M, Khandelwal N. Computed tomography imaging based normative orbital measurement in Indian population. Indian Journal of Ophthalmology. 2019;67(5):659.

[2] Sheikh M, Abalkhail S, Doi S, Al-Shoumer K. Normal measurement of orbita structures: Implications for the assessment of Graves' ophthalmopathy. Australasian Radiology. 2007;51(3):253-56.

[3] Chatdokmaiprai C, Kiranantawat K, Lertsithichai P, Taeshineetanakul P. Normative data of the interorbital distance in Thai population: Journal of Craniofacial Surgery. 2018;29(7):1939-44

[4] Mekala D, Shubha R, Rohini M. Orbital dimensions and orbital index: A measurement study on South Indian Dry Skull. Int J Anatomy Res. 2015;3(3):1387-91.

[5] Dhanwate AD, Gaikwad MD. Morphometric analysis of orbit in Indian skulls and comparison with international studies. Int J Anat Res. 2016;4(4):2896-01.

[6] Khademi Z, Bayat P. Computed tomographic measurements of orbital entrance dimensions in relation to age and gender in a sample of healthy Iranian population. Journal of Current Ophthalmology. 2016;28(2):81-84.

[7] Nugent RA, Belkin RI, Neigel JM, Rootman J, Robertson WD, Spinelli J, et al. Graves orbitopathy: Correlation of CT and clinical findings. Radiology. 1990;177:675-82.

[8] Lee JS, Lim DW, Lee SH, Oum BS, Kim HJ, Lee HJ. Normative measurements of Korean orbital structures revealed by computerized tomography. Acta ophthalmologica Scandinavica. 2001;79(2):197-200.

[9] Dubost C, Le Gouez A, Jouffroy V, Roger-Christoph S, Benhamou D, Mercier FJ, et al. Optic nerve sheath diameter used as ultra sonographic assessment of the incidence of raised intracranial pressure in preeclampsia a pilot study. Anesthesiology: The Journal of the American Society of Anesthesiologists. 2012;116(5):1066-71.

[10] Mafee MF, Pruzansky S, Corrales MM, Phatak MG, Valvassori GE, Dobben GD, et al. CT in the evaluation of the orbit and the bony interorbital distance. American Journal of Neuroradiology. 1986;7(2):265-69.

[11] Vasanthakumar P, Kumar P, Rao M. Anthropometric analysis of palpebra fissure dimensions and its position in south Indian ethnic adults. Oman Med J. 2013;28:26-32

[12] Kumar A, Nagar M. Morphometry of the orbital region: "Beauty is bought by judgment of the eyes." Int J Anat Res. 2014;2(3):566-70.

[13] Kaur J, Yadav S, Singh Z. Orbital dimensions-A direct measurement study using dry skulls. J Acad Indus Res. 2012;1(6):293-95.

[14] Jullabussapa N, Khwanngern K, Pateekhum C, Angkurawaranon C, Angkurawaranon S. CT-Based measurements of facial parameters of healthy children and adolescents in Thailand. American Journal of Neuroradiology. 2020;41(10):1937-42

PARTICULARS OF CONTRIBUTORS:

1. Senior Resident, Department of Radiology, Raja Rajeswari Medical College and Hospital, Bangalore, Karnataka, India

2. Junior Resident, Department of Radiology, Raja Rajeswari Medical College and Hospital, Bangalore, Karnataka, India.

NAME, ADDRESS, E-MAIL ID OF THE CORRESPONDING AUTHOR:

Sanket Vinubhai Davra,

Department of Radiodiagnosis, Rajarajeswari Medical College and Hospital,

Bangalore, Karnataka, India.

E-mail: davrasanket@gmail.com

\section{AUTHOR DECLARATION:}

- Financial or Other Competing Interests: None

- Was Ethics Committee Approval obtained for this study? Yes

- Was informed consent obtained from the subjects involved in the study? Yes

- For any images presented appropriate consent has been obtained from the subjects. Yes
PLAGIARISM CHECKING METHODS: Jain Het al.]

- Plagiarism X-checker: Sep 22, 2020

- Manual Googling: Mar 30, 2021

- iThenticate Software: Apr 23, 2021 (9\%)
ETYMOLOGY: Author Origin

Date of Submission: Sep 20, 2020

Date of Peer Review: Nov 23, 2020

Date of Acceptance: Mar 31, 2021

Date of Publishing: Jul 01, 2021 